\title{
Tabebuia impetiginosa (Mart. Ex DC. Mattos) Bark Extracts Inhibit the Growth Gastrointestinal Bacterial Pathogens and Potentiate the Activity of some Conventional Antibiotics
}

\author{
Alejandra Fernandez ${ }^{1,2}$, lan Edwin Cock ${ }^{1,2, *}$ \\ 'School of Environment and Science, Griffith University, 170 Kessels Rd, Nathan, Brisbane, Queensland, AUSTRALIA. \\ ¿Environmental Futures Research Institute, Griffith University, 170 Kessels Rd, Nathan, Brisbane, Queensland, AUSTRALIA.
}

\begin{abstract}
Introduction: Tabebuia impetiginosa (Mart. Ex DC. Mattos) bark has been used to treat inflammation and cancer, as well as a variety of pathogenic diseases, in traditional South American healing systems. As practitioners of complementary medicine frequently use herbal medicines concurrently with conventional antibiotics, the effects of both therapies in combination needs to be evaluated. Methods: The growth inhibitory activity of T. impetiginosa bark extracts was assessed against a panel of gastrointestinal bacterial pathogens by standard disc diffusion and liquid dilution minimum inhibitory concentration (MIC) methods. Combinational effects between the extracts and conventional antimicrobials were classified using the sum of the fractional inhibitory concentration. The toxicity of the individual samples and combinations was evaluated by Artemia lethality and MTS HDF cell viability assays. Results: T. impetiginosa bark extracts strongly inhibited the growth of $B$. cereus but were ineffective against Escherichia coli, Shigella sonnei, Staphylococcus aureus. The mid polarity ethyl acetate extract was a particularly good inhibitor of $B$. cereus growth (DD and LD MIC values of 45 and $245 \mu \mathrm{g} / \mathrm{mL}$ respectively). However, the effects of combinations of the extracts and conventional antibiotics was of considerably more interest. Although no synergistic interactions were noted, the potency of some combinations were substantially potentiated compared to activity of the individual components. Additive potentiation was was noted for combinations containing the T. impetiginosa water extract and erythromycin, chloramphenicol or penicillin-G against $E$. coli and
\end{abstract}

S. aureus. Combinations containing ciprofloxacin also produced additive effects against all of the bacteria tested. Therefore, these combinations have enhanced benefits over either component alone. Of further note, antagonistic interactions were also detected in several combinations containing ciprofloxacin (particularly against $S$. aureus). These combinations should therefore be avoided against that bacterium. Conclusion: T. impetiginosa bark extracts inhibit the growth of $B$. cereus when tested alone and potentiated the activity of some conventional antibiotics against a panel of gastrointestinal pathogens when used in combination. Thus, T. impetiginosa bark extracts have potential in the treatment of diarrhoea and other gastrointestinal diseases.

Key words: Pau d'arco, Gastrointestinal disease, Diarrhoea, Bacillus cereus, Escherichia coli, Shigella sonnei, Staphylococcus aureau, Lapachol.

\section{Correspondence:}

Dr. Ian Edwin Cock

'School of Environment and Science, Griffith University, 170 Kessels Rd, Nathan, Brisbane, Queensland-4111, AUSTRALIA.

${ }^{2}$ Environmental Futures Research Institute, Griffith University, 170 Kessels Rd, Nathan, Brisbane, Queensland-4111, AUSTRALIA.

Phone no: +61 737357637

E-mail: i.cock@griffith.edu.au

DOI: $10.5530 /$ pc.2020.2.15

\section{INTRODUCTION}

The discovery of penicillin by Alexander Flemming nearly a hundred years ago caused a major paradigm shift in the way that medical research sought to develop new antibiotic chemotherapies. Since that time, research has focussed on screening microbially derived compounds for antibiotic activity. This method of discovery has provided the majority of our first generation drugs. However, bacteria have developed resistance to all of these antibiotics, generally within a couple of years of their incorporation into clinical use. ${ }^{1}$ Many medicinally important bacterial pathogens have become either extremely (XDR) or totally drug resistant (TDR) to commonly used antibiotics ${ }^{1}$ and there are now limited therapeutic options to eradicate these pathogens. This problem is expected to worsen as bacteria further exchange resistance genes, rendering more bacterial strains multi-drug resistant (MDR). The development of alternative antibacterial treatment modalities has become crucial and one of the most serious challenges currently facing medical science. For a number of reasons reviewed elsewhere, ${ }^{1}$ it is unlikely that the previous methods of antibiotic discovery/development will be as successful in the future and new treatment modalities are urgently required.

This problem is particularly evident for infectious gastrointestinal disease as the gastrointestinal milieu provides an ideal medium for the exchange of genetic material. As a result, nearly nine million children under the age of five die every year from diarrhoeal related illnesses. ${ }^{2}$ Indeed, diarrhoea is the leading killer of children globally, accounting for $9 \%$ of all deaths among children under the age of five. ${ }^{3}$ This equates to more than 1400 young children dying each day, or about 530,000 children a year. Many gastrointestinal bacterial pathogens have developed resistance to conventional antibiotics, rendering them useless against some diarrhoea causing pathogens. There is an urgent need to develop new treatment options to combat these diseases, either through the development of novel drugs, or through new therapies enabling previously effective antibiotics to function with increased efficacy again. Many plants used in traditional medicinal systems are effective in the treatment of diarrhoea and their usage is often well documented, aiding in species selection. These traditional medicines are often used separately, or may be prescribed in combination. The multiple negative effects of diarrhoea (loose stools, cramps, loss of electrolytes and possible fever) have been targeted by combining different medicinal plants for either a synergistic effect or to treat the different symptoms. Combinational therapies including one or more plant extract, often results in synergy and a far better therapeutic outcomes than any of the components alone. $^{4-7}$

Traditional medicines and herbal remedies have great potential for antimicrobial drug development and there has recently been a substantial increase in interest in this field. ${ }^{8-10}$ Tabebuia impetiginosa (Mart. Ex DC. Mattos) (synonyms Tabebuia palmeri Rose, Handroanthus avellanedae Lorentz ex Griseb.; common names Pau d'arco (Portuguese), Lapacho (Spanish) and Trumpet tree (English)) has been used by indigenous South Americans as a remedy for inflammation, cancer, syphilis, malaria, 
fevers, trypanosomiasis, fungal and bacterial infections, as well as to treat stomach disorders. ${ }^{11}$ The bark is particularly well known as an effective immunostimulant and inflammatory modulator and recent studies have demonstrated that $T$. impetiginosa bark has immunomodulatory effects. A recent study reported that $T$. impetiginosa bark were potent inhibitors of pro-inflammatory cytokine secretion, reducing the levels of both PMA-induced and LPS-induced cytokines and chemokines by greater than $95 \% .{ }^{12}$ That study reported significant modulation of IFN- $\gamma$, IL- $1 \beta$, IL-2, IL-6, IL-8, IL-10, MCP-1 and TNF- $\alpha$ levels. Another study tested similar extracts against the bacterial triggers of earlier phases of the progression of some autoimmune diseases. ${ }^{13}$ That study highlighted the potent antibacterial activity of these extracts against these autoimmune disease associated pathogens. Despite this, the growth inhibitory activity of T. impetiginosa extracts against other bacterial pathogens is lacking. Our study was undertaken to examine the effects of T. impetiginosa bark extracts on some gastrointestinal bacterial pathogens associated with diarrhoea. The aim of this project is to investigate the efficacy of the traditional South American medicinal plant (alone and in combination with conventional antibiotics) against pathogens which cause diarrhoea.

\section{MATERIALS AND METHODS}

\section{Plant material and extraction}

T. impetiginosa (Mart. Ex. DC. Mattos) bark was supplied by Noodles Emporium, Australia (an online herbal supplier) and were originally sourced from verified trees in Peru. The sample was stored at $-30^{\circ} \mathrm{C}$ until processing. Individual $1 \mathrm{~g}$ masses of bark were weighed and transferred into five $50 \mathrm{~mL}$ Falcon tubes tubes. Each tube was filled with $50 \mathrm{~mL}$ of individual solvents of varying polarity (water, methanol, ethyl acetate, chloroform and hexane). All solvents were obtained from Ajax Fine Chemicals, Australia and were AR grade. The bark was extracted for $24 \mathrm{hr}$ with gentle oscillation. The resultant extracts were filtered into new tubes using Whatman No. 54 filter paper. The extracts were subsequently dried at $40^{\circ} \mathrm{C}$ in an vacuum incubator until the solvents had completely evaporated. The dried products were weighed and dissolved in $10 \mathrm{~mL}$ deionised water (containing 1\% DMSO) and syringe filtered using Millipore $0.22 \mu \mathrm{m}$ membrane filters). The extracts were stored at $4^{\circ} \mathrm{C}$ until further use.

\section{Qualitative phytochemical studies}

Qualitative phytochemical analysis of the T. impetiginosa extracts to detect the presence of saponins, phenolic compounds, flavonoids, phytosteroids, triterpenoids, cardiac glycosides, anthraquinones, tannins and alkaloids and evaluate their relative abundances was conducted using standard assays. ${ }^{14,15}$

\section{Antibacterial screening Conventional antibiotics}

Chloramphenicol ( $\geq 98 \%$ purity), erythromycin $(\geq 850 \mu \mathrm{g} / \mathrm{mg})$, gentamicin $(600 \mu \mathrm{g} / \mathrm{mg})$, penicillin-G $(1440-1680 \mu \mathrm{g} / \mathrm{mg})$ and tetracycline $(\geq 95 \%$ purity) were purchased from Sigma-Aldrich, Australia. All antibiotics were prepared as $0.01 \mathrm{mg} / \mathrm{mL}$ stocks in sterile deionised water. For the disc diffusion studies, pre-loaded ampicillin $(2 \mu \mathrm{g})$ and chloramphenicol $(10 \mu \mathrm{g})$ susceptibility discs (Oxoid Ltd., Australia) were used as positive controls.

\section{Test microorganisms}

All media was obtained from Oxoid Ltd., Australia and prepared as per manufacturer's instructions. A reference strain of was E. coli (ATCC K12) purchased from American Tissue Culture Collection, USA. The clinical strains of Bacillus cereus, Shigella sonnei and S. aureus, were kindly provided by the School of Environment and Science teaching laboratory,
Griffith University. All bacterial strains were individually cultured to log phase in nutrient broth (Oxoid Ltd., Australia). Streak nutrient agar (Oxoid Ltd., Australia) plates were cultured in parallel to ensure the purity of all bacterial cultures and to allow for sub-culturing. All cultures were incubated at $37^{\circ} \mathrm{C}$ for $24 \mathrm{hr}$ and were maintained in nutrient broth at $4^{\circ} \mathrm{C}$.

\section{Antimicrobial activity screening}

The T. impetiginosa bark extracts were initially screened undiluted using a standard disc diffusion assay as previously described. ${ }^{16,17}$ Briefly, individual bacterial suspensions $(100 \mu \mathrm{L})$ was spread evenly onto nutrient agar plates and $6 \mathrm{~mm}$ filter paper discs infused with individual extracts were placed onto the surface of the plates. The plates were incubated at $37^{\circ} \mathrm{C}$ for $24 \mathrm{hr}$ and the diameters of the zones of inhibition (ZOI) were subsequently measured and are expressed as the mean values ( \pm SEM) of three independent experiments, each with internal triplicate measure-

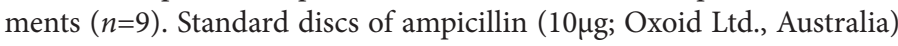
and discs infused with $10 \mu \mathrm{L}$ of distilled water (containing 1\% DMSO) were included on each agar plate as a positive and negative controls respectively.

\section{Minimum inhibitory concentration (MIC) determination}

The minimum inhibitory concentration for each extract was determined using liquid dilution MIC assays and solid phase agar disc diffusion assays.

\section{Microplate liquid dilution MIC assay}

A standard liquid dilution MIC assay ${ }^{18,19}$ was used to evaluate the bacterial growth inhibitory activity of the extracts and conventional antibiotics, both independently and as combinations. Briefly, log phase bacterial cultures were diluted to produce a McFarlands inoculation culture. ${ }^{18,19} \mathrm{~A}$ $100 \mu \mathrm{L}$ volume of sterilized nutrient broth was dispensed into all wells of a 96 well micro-titre plate. Then, $100 \mu \mathrm{L}$ of the plant extracts or conventional antibiotics were dispensed into separate wells of the top row of the plate. A negative control (nutrient broth), sterile control (broth without bacteria) and a sample-free culture control (to ensure the media was capable of supporting microbial growth) were also included on all plates. Each test sample or control was serially diluted down each column on the plate by doubling dilution. The assay culture inoculum $(100 \mu \mathrm{L}$, containing approximately $1 \times 10^{6}$ colony forming units $(\mathrm{CFU}) / \mathrm{mL}$ ) was then added to all wells except the sterile control wells and incubated overnight at $37^{\circ} \mathrm{C}$. p-Iodonitrotetrazolium violet (INT, Sigma-Aldrich, Australia) was dissolved in sterile deionised water to a concentration of $0.2 \mathrm{mg} / \mathrm{mL}$. A volume of $40 \mu \mathrm{L}$ of the INT solution was added into all wells and the plate was incubated for a further $6 \mathrm{hr}$ at $37^{\circ} \mathrm{C}$. The MIC was visually determined as the lowest dose at which colour development was inhibited.

\section{Disc diffusion MIC assay}

The minimum inhibitory concentration (MIC) of each extract was also quantified by disc diffusion assay. ${ }^{16,17}$ Graphs of the zone of inhibition (ZOI) versus ln concentration were plotted and MIC values were calculated by linear regression.

\section{Extract-conventional antibiotic interaction studies: Fractional inhibitory concentration (FIC) assessment}

Interactions between the plant samples and conventional antimicrobials were detected and classified via determination of the sum of the fractional inhibitory concentration ( $\mathrm{FIC}$ ). The FIC was calculated using the following equation, where (a) represents the plant sample and (b) the conventional antibiotic sample: ${ }^{20,21}$

$$
\mathrm{FIC}^{(\mathrm{i})}=\frac{\text { MIC }(\mathrm{a}) \text { in combination with (b) }}{\text { MIC (a) independently }}
$$




\section{$\mathrm{FIC}^{(\mathrm{ii})}=\quad \frac{\text { MIC (b) in combination with (a) }}{\text { MIC (b) independently }}$}

The $\Sigma$ FIC was then calculated using the equation: $\Sigma F I C=\mathrm{FIC}^{(\mathrm{i})}+\mathrm{FIC}^{(\mathrm{ii})}$. The interactions were classified as being synergistic for $\sum$ FIC values of $\leq$ 0.5 , additive $(>0.5-1.0)$, indifferent $(>1.0-\leq 4.0)$ or antagonistic $(>4.0){ }^{7}$

\section{Toxicity evaluation}

Two assays were used to evaluate and quantify the toxicity of the extracts. The Artemia lethality assay (ALA) was utilised for rapid preliminary toxicity assessment. An MTS-based cellular proliferation assay was used as a cellular evaluation of the extract's toxicity.

\section{Artemia franciscana nauplii toxicity screening}

Toxicity was evaluated using an A. franciscana nauplii (brine shrimp) lethality assay, modified for testing plant extracts. ${ }^{22,23}$ Potassium dichromate $\left(\mathrm{K}_{2} \mathrm{Cr}_{2} \mathrm{O}_{7}\right)$ (AR grade, Chem-Supply, Australia) was prepared in distilled water as a $1.6 \mathrm{mg} / \mathrm{mL}$ solution and used as a reference toxin in the Artemia franciscana nauplii bioassay. A. franciscana nauplii were incubated in the presence of the test extracts, reference toxin or artificial seawater (negative control) at $25 \pm 1^{\circ} \mathrm{C}$ under artificial light (1000 Lux). All treatments were performed three times in triplicate $(n=9)$. The number of dead were counted in each well at $24 \mathrm{hr}$ and the remaining live nauplii were then sacrificed and the total number of nauplii in each well were counted and used to calculate the \% mortality per well. LC $_{50}$ values were calculated for each treatment using probit analysis.

\section{Cellular viability assay}

The T. impetiginosa bark extracts were screened against normal human primary dermal fibroblasts (HDF; American Type Culture Collection (ATCC PCS-201-012)) using conventional assays. ${ }^{24}$ Briefly, aliquots of the HDF cells $(70 \mu \mathrm{L}$, containing approximately 5000 cells) were added to individual wells of a 96 well plate. The test extracts or controls $(30 \mu \mathrm{L})$ were added to individual wells and the plates were incubated at $37^{\circ} \mathrm{C}$, $5 \% \mathrm{CO}_{2}$ for $24 \mathrm{hr}$ in a humidified atmosphere. All extracts were initially tested at $200 \mu \mathrm{g} / \mathrm{mL}$. Following a wash in PBS ( $\mathrm{pH} 7.2$ ) to remove interference due to sample colour, $20 \mu \mathrm{L}$ of Cell Titre 96 Aqueous One solution (Promega) was added to all wells and re-incubated at $37^{\circ} \mathrm{C}$ for a further $3 \mathrm{hr}$. Absorbances were recorded at a test wavelength of $540 \mathrm{~nm}$ and a blank wavelength of $690 \mathrm{~nm}$ using a Molecular Devices, Spectra Max M3 plate reader. All tests were performed three times, each with internal triplicates $(n=9)$. The $\%$ cellular viability of each test was calculated using the following formula:

$\%$ cellular viability $=\frac{\text { Abs test sample }-(\text { mean Abs control-mean Abs blank })}{(\text { mean } \text { Abs control-mean Abs blank })}$

Less than $50 \%$ cellular viability indicated toxicity, whereas tests with $>50 \%$ untreated control viability were defined as non-toxic.

\section{Statistical analysis}

Data are expressed as the mean \pm standard deviation (SD) of three independent experiments, each with internal triplicates $(n=9)$. One way ANOVA was used to calculate statistical significance between control and treated groups, with $P$ values $<0.01$ considered statistically significant.

\section{RESULTS}

\section{Extraction yields and qualitative phytochemical screening}

Extraction of $1 \mathrm{~g}$ masses of dried T. impetiginosa bark with various solvents yielded dried plant extracts ranging from $51.3 \mathrm{mg}$ (water extract) to $79.3 \mathrm{mg}$ (hexane extract) (Table 1). Methanol and hexane gave the highest yields of dried extract material, whilst all other solvents extracted lower masses. The dried extracts were resuspended in $10 \mathrm{~mL}$ of deionised water (containing 1\% DMSO), resulting in the extract concentrations shown in Table 1. Qualitative phytochemical studies (Table 1) showed that methanol extracted the widest range of phytochemicals, with high levels of phenolic compounds, cardiac glycosides, triterpenoids, flavonoids and alkaloids detected. The water extract had high levels of phenolics, cardiac glycosides, saponins, triterpenoids and alkaloids. Ethyl acetate extracted high levels of water insoluble phenols, saponins, triterpenoids and alkaloids, as well as moderate levels of flavonoids and low levels of phenolic compounds. Similarly, the chloroform extract contained high levels of saponins, triterpenoids, alkaloids, as well as low levels of phenolic compounds and flavonoids. Hexane extracted the narrowest range of phytochemicals, with water insoluble phenols and alkaloids present in the highest relative abundance. Low levels of phenolic compounds, triterpenoids and flavonoids were also detected in the hexane extract.

\section{Antibacterial activity}

To examine the growth inhibitory activity of the T. impetiginosa bark extracts, a series of disc diffusion assays were conducted on nutrient agar plates inoculated with diarrhoea causing bacterial strains (B. cereus, E. coli, S. sonnei and S. aureus). B. cereus growth was inhibited by all of the T. impetiginosa bark extracts except the aqueous extract (Figure 1). The methanolic extract had the strongest antibacterial effects, with zones of inhibition of $8.6 \pm 0.4 \mathrm{~mm}$. The zones of inhibition of the other extracts ranged from approximately $7.2-7.6 \mathrm{~mm}$. These zones of inhibition are indicative of low to moderate growth inhibition. However, this bacterial strain was also somewhat resistant to ampicillin. Therefore, these extracts may still have potential for the prevention and treatment of $B$. cereus infections. In contrast, chloramphenicol was a relatively good inhibitor of $B$. cereus growth. No growth inhibitory activity was observed for any of the extracts against any of the other bacterial species.

The minimum inhibitory concentration for each extract was determined by further analysing the extracts that showed antimicrobial activity against $B$. cereus across a range of concentrations in the disc diffusion and liquid dilution MIC assays (Table 2). MIC values for the antibiotic controls are only provided for the liquid dilution assays as the standard antibiotic control discs used for the disc diffusion assay were only tested at a single dose. The T. impetiginosa bark extracts only inhibited the growth of $B$. cereus. No inhibition was noted against any of the other bacteria in either assay system so no MIC values are recorded here. Similarly, the aqueous extract was completely ineffective against $B$. cereus so an MIC value is also not recorded. In contrast, the methanolic, ethyl acetate, chloroform and hexane extracts displayed MIC values substantially $<1000 \mu \mathrm{g} / \mathrm{mL}$ against $B$. cereus, indicating good growth inhibitory properties. Indeed, the ethyl acetate extract had MIC values of 54 and $245 \mu \mathrm{g} / \mathrm{mL}$ in the disc diffusion and liquid dilution MIC assays respectively. The hexane extract was the next strongest inhibitor of $B$. cereus growth, followed by the methanol and chloroform extracts. These results indicate that the active component(s) within these extracts may be mid to low polarity.

\section{Combinational effects on bacterial gastrointestinal pathogens}

The LD assay was also used to study combinational effects of the T. impetiginosa bark extracts in combination with six conventional antibiotics (tetracycline, gentamycin, erythromycin, chloramphenicol, penicillin-G and ciprofloxacin). The $\Sigma$ FIC values calculated in this study (Table 3) were used to distinguish between synergistic, additive, non-interactive and antagonistic combinational effects. None of the combinations resulted in synergy. The majority of the combinations had little benefit when 
Table 1: Extraction yields and qualitative phytochemical screenings of T. impetiginosa bark extracts.

\begin{tabular}{|c|c|c|c|c|c|}
\hline Extract & $\mathrm{H}_{2} \mathrm{O}$ & $\mathrm{MeOH}$ & ETAC & $\mathrm{CHCl}_{3}$ & HEX \\
\hline Mass of extract (mg) & 51.3 & 76.1 & 63.8 & 65.5 & 79.3 \\
\hline Concentration of the extract $(\mathrm{mg} / \mathrm{mL})$ & 5.13 & 7.61 & 6.38 & 6.55 & 7.93 \\
\hline Phenolic compounds & +++ & +++ & + & + & + \\
\hline Water soluble phenols & + & ++ & - & - & - \\
\hline Water insoluble phenols & - & +++ & +++ & +++ & +++ \\
\hline Cardiac glycosides & +++ & +++ & - & - & - \\
\hline Polysteroids & - & - & - & - & - \\
\hline Saponins & +++ & - & +++ & +++ & - \\
\hline Triterpenoids & +++ & +++ & +++ & +++ & + \\
\hline Flavonoids & - & +++ & ++ & + & + \\
\hline Free anthraquinones & - & - & - & - & - \\
\hline Combined anthraquinones & - & - & - & - & - \\
\hline Mayer reagent test (alkaloids) & +++ & +++ & +++ & +++ & +++ \\
\hline Wagner's reagent test (alkaloids) & +++ & +++ & +++ & +++ & +++ \\
\hline
\end{tabular}

$\mathbf{H}_{2} \mathbf{O}=$ water extract $\mathbf{M e O H}=$ methanol extract; $\mathbf{E T A C}=$ ethyl acetate extract; $\mathbf{C H C l}_{3}=$ chloroform extract; $\mathbf{H E X}=$ hexane extract; +++ indicates a strong response; ++ indicates a moderate response; + indicates a minor response; - indicates no response in the assay

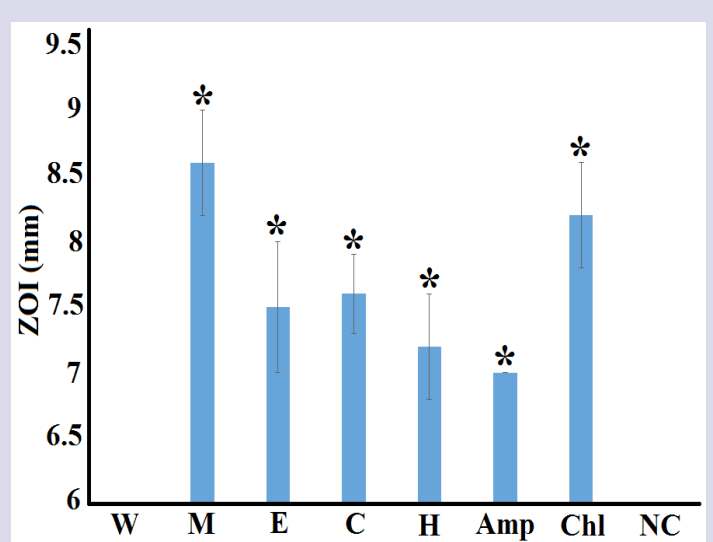

Figure 1: Antibacterial activity of the T. impetiginosa bark extracts against a clinical $B$. cereus strain measured as zones of inhibition $(\mathrm{mm})$. $\mathrm{W}=$ aqueous extract; $\mathrm{M}=$ methanolic extract; $\mathrm{E}=$ ethyl acetate extract; $\mathrm{C}=$ chloroform extract; $\mathrm{H}=$ hexane extract. Positive controls: $\mathrm{Amp}=\mathrm{am}-$ picillin $(10 \mu \mathrm{g}) ; \mathrm{Chl}=$ chloramphenicol $(10 \mu \mathrm{g})$; Negative control $(\mathrm{NC})=$ water. Results are expressed as mean zones of inhibition of at least six replicates (two repeats) \pm SEM. * indicates results that are significantly different to the negative control $(P<0.01)$.

tested against E. coli. When the extracts were combined with gentamicin, all combinations were classified as indifferent ( $\Sigma$ FICs ranging from 1.62-2.09; Table 3). Similarly, the ethyl acetate and chloroform extracts produced indifferent interactions when combined with ciprofloxacin ( $\Sigma$ FICs of 3.03 and 1.62 respectively). However, additive reactions were observed when combining the polar aqueous and methanolic extracts with erythromycin, chloramphenicol or penicillin-G, with $\Sigma$ FIC values of 0.6 recorded. When the aqueous or methanolic extracts were combined with ciprofloxacin, an $\Sigma$ FIC of 1 was observed, also indicating additive effects. Therefore, these combinations may have some benefits

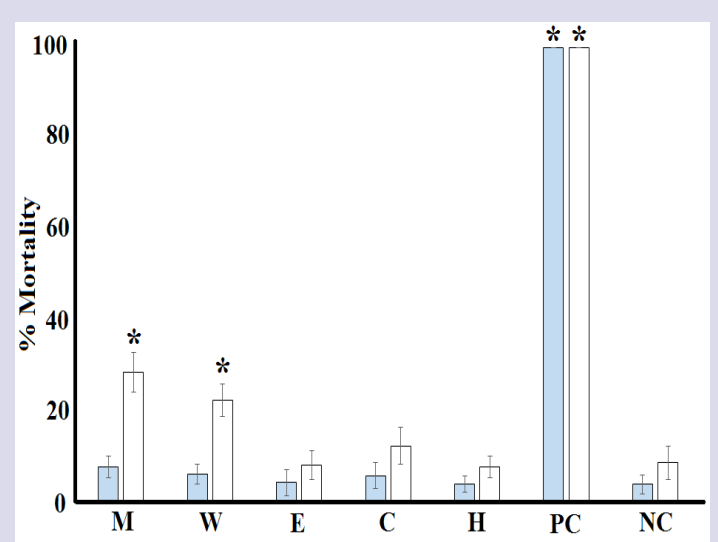

Figure 2: The lethality of the T. impetiginosa bark extracts, potassium dichromate control $(1000 \mu \mathrm{g} / \mathrm{mL})$ and seawater (negative control). Shaded bars represent the mortality induced by the $T$. impetiginosa extracts following $24 \mathrm{hr}$ exposure; open bars represent the mortality induced by the $T$. impetiginosa extracts following $48 \mathrm{hr}$ exposure. All bioassays were performed three times in triplicate $(n=9)$ and are expressed as mean \pm SD. ${ }^{*}$ indicates results that are significantly different to the untreated (seawater) control at the equivalent exposure time $(P<0.01)$.

in treating diarrhoea caused by these pathogens, compared to the effects of the extracts or the antibiotic when used alone.

When the T. impetiginosa bark extracts were tested in combination with the conventional antibiotics against $B$. cereus, most had no activity. Of the combinations that inhibited $B$. cereus growth, most produced indifferent effects. Indeed, all of the combinations containing gentamicin were noninteractive. Interestingly, when the ethyl acetate or chloroform extracts were combined with ciprofloxacin, additive effects were noted ( $\Sigma$ FICs of 0.51 and 1 respectively). These combinations have enhanced efficacy compared to either component when used alone. Therefore, the use of 
Table 2: Disc diffusion (DD) and liquid dilution (LD) MIC values for T. impetiginosa bark extracts against E. coli (ATCC: K12) and the clinical strains of $B$. cereus, S. sonneii and S. aureus growth $(\mu \mathrm{g} / \mathrm{mL})$.

\begin{tabular}{|c|c|c|c|c|c|c|c|c|}
\hline \multirow{2}{*}{ EXTRACT } & \multicolumn{2}{|c|}{ E. coli (ATCC: K12) } & \multicolumn{2}{|c|}{ B. cereus $(\mathrm{CI})$} & \multicolumn{2}{|c|}{ S. sonneii $(\mathrm{Cl})$} & \multicolumn{2}{|c|}{ S. aureus (CI) } \\
\hline & DD MIC & LD MIC & DD MIC & LD MIC & DD MIC & LD MIC & DD MIC & LD MIC \\
\hline $\mathrm{TIH}_{2} \mathrm{O}$ & - & - & - & - & - & - & - & - \\
\hline TIMeOH & - & - & 643 & 480 & - & - & - & - \\
\hline TIETAC & - & - & 53.6 & 245 & - & - & - & - \\
\hline $\mathrm{TICHCl}_{3}$ & - & - & 797.2 & 840 & - & - & - & - \\
\hline TIHEX & - & - & 425.5 & 755 & - & - & - & - \\
\hline \multicolumn{9}{|c|}{ Positive controls } \\
\hline Tetracycline & ND & - & ND & - & ND & 2.5 & ND & - \\
\hline Gentamicin & ND & 0.4 & ND & 0.3 & ND & 0.3 & ND & 0.3 \\
\hline Erythromycin & ND & 0.01 & ND & - & ND & - & ND & - \\
\hline Chloramphenicol & ND & - & ND & - & ND & - & ND & - \\
\hline Penicillin G & ND & - & ND & - & ND & - & ND & - \\
\hline Ciprofloxacin & ND & 0.2 & ND & 0.2 & ND & 0.08 & ND & 0.2 \\
\hline \multicolumn{9}{|l|}{ Negative control } \\
\hline $\begin{array}{l}\text { 1\% DMSO (DD)/ nutrient } \\
\text { broth (LD) }\end{array}$ & ND & - & ND & - & ND & - & ND & - \\
\hline
\end{tabular}

$\mathrm{TI}=$ T. impetiginosa $\mathbf{\mathbf { H } _ { 2 }} \mathbf{O}=$ water $\mathbf{M e O H}=$ methanol; $\mathbf{E T A C}=$ ethyl acetate; $\mathbf{C H C l}_{3}=$ chloroform; $\mathbf{H E X}=$ hexane; $\mathbf{D D}=$ Disc Diffusion; $\mathbf{L D}=$ Liquid Dilution; - = No inhibition; numbers indicate the mean DD MIC and LD MIC values of triplicate determinations, expressed in $\mu \mathrm{g} / \mathrm{mL} ; \mathrm{ND}=$ MIC could not be determined as only standard discs containing a fixed dose were used.

these combinations is beneficial in the treatment of diarrhoea caused by B. cereus. Interestingly, when the water extract was combined with ciprofloxacin, antagonism was observed ( FIC of 5, Table 3). Therefore, this combination should be avoided when treating diarrhoea.

Four additive interactions were observed when the methanol, ethyl acetate, chloroform or hexane extracts were tested with ciprofloxacin $(\Sigma F I C s$ of 1 ) against $S$. sonnei, whereas most of the combinations with gentamicin were indifferent. No other combination showed combinational effects against S. sonnei. Similarly, when the T. impetiginosa bark extracts were combined with the antibiotics and tested against $S$. aureus, most of the reactions were classified as indifferent. However, when the water extract was combined with erythromycin, chloramphenicol or penicillin$\mathrm{G}$, additive effects were observed, with $\Sigma$ FICs of 1 . Therefore, the use of these combinations would be beneficial for the treatment of $S$. aureus induced gastrointestinal disease. Notably, when combining the aqueous, methanolic or the ethyl acetate extract with ciprofloxacin, antagonistic effects were observed ( $\Sigma$ FICs of 4.5, 8.1 and 8.1 respectively). Therefore, these combinations should be avoided when treating diarrhoea.

\section{Quantification of toxicity}

All extracts were initially screened undiluted in the assay in parallel with the reference toxin potassium dichromate $(1000 \mu \mathrm{g} / \mathrm{mL})$ (Figure 2). The toxic effects of potassium dichromate were evident within the first $4 \mathrm{hr}$ of exposure, with $100 \%$ mortality achieved following $6 \mathrm{hr}$ exposure (results not shown). In contrast, all extracts induced substantially $<50 \%$ mortality at all concentrations screened and were therefore deemed to be nontoxic and $\mathrm{LC}_{50}$ values could not be determined. The T. impetiginosa bark extracts were also screened against human dermal fibroblasts (HDF) in the cell viability assay. In this assay, extracts producing $<50 \%$ cell viability at $200 \mu \mathrm{g} / \mathrm{mL}$ are deemed to be toxic. ${ }^{25,26}$ None of the extracts induced changes in \% cell viability that were significantly different from the untreated control values. Therefore, $\mathrm{LC}_{50}$ values could not be determined for these extracts. All extracts were deemed to be non-toxic. In contrast, toxicity of the positive control (quinine) was confirmed, with a $\mathrm{LC}_{50}$ value of $46 \mu \mathrm{g} / \mathrm{mL}$ calculated, indicating that the assay was functioning properly.

\section{DISCUSSION}

Diarrhoea remains a leading killer of children, accounting for $8 \%$ of all death among children under the age of 5 die. ${ }^{27}$ Indeed, more than half a million children in this age group die each year from diarrhoeal disease, ${ }^{28}$ which equates to over 1400 deaths per day. Furthermore, as bacterial pathogens develop further resistance to conventional antibiotics, medicines are expected to have reduced efficacy against diarrhoeal diseases and increases in mortality rates are expected. ${ }^{28,29}$ There is an urgent need to develop new therapeutic options to combat these illnesses, either through novel drug molecules or by utilizing new therapy regimens that enable (or re-purpose) previously effective antibiotics that have lost their potency due to the emergence of highly resistant infections to become useful again.

Many plants used in traditional medicinal systems are effective in the treatment of diarrhoea. T. impetiginosa bark has been used for thousands of years by indigenous South Americans to treat inflammation, cancer, syphilis, malaria, fevers, trypanosomiasis, fungal and bacterial infections, as well as stomach disorders. ${ }^{11}$ Studies on the antibacterial properties of T. impetiginosa bark are relatively lacking and much more work is required in this area. Recent studies have reported that T. impetiginosa bark extracts are potent inhibitors of pro-infammatory cytokine 
Table 3: Combinational effects of the T. impetigosa extracts and conventional antibiotics on the bacterial gastrointestinal pathogens.

\begin{tabular}{|c|c|c|c|c|c|c|}
\hline \multicolumn{7}{|c|}{ E. coli (ATCC K12) } \\
\hline Extracts & Tetracycline & Gentamycin & Erythromycin & Chloramphenicol & Penicillin-G & Ciprofloxacin \\
\hline $\mathrm{TIH}_{2} \mathrm{O}$ & - & 2.1 & 0.6 & 0.6 & 0.6 & 1 \\
\hline TIMeOH & - & 1.8 & 0.6 & 0.6 & - & 1 \\
\hline TIETAC & - & 1.6 & - & - & - & 3 \\
\hline $\mathrm{TICHCl}_{3}$ & - & 1.8 & - & - & - & 1.6 \\
\hline TIHEX & - & 1.8 & - & - & - & 1 \\
\hline \multicolumn{7}{|c|}{ B. cereus clinical strain } \\
\hline Extracts & Tetracycline & Gentamycin & Erythromycin & Chloramphenicol & Penicillin-G & Ciprofloxacin \\
\hline $\mathrm{TIH}_{2} \mathrm{O}$ & - & 2.5 & 1.1 & 1.1 & 1.1 & $\underline{5}$ \\
\hline TIMeOH & - & 2.3 & - & - & - & 2.3 \\
\hline TIETAC & - & 1.1 & - & - & - & 0.51 \\
\hline $\mathrm{TICHCl}_{3}$ & - & 1.1 & - & - & - & 1 \\
\hline TIHEX & - & 1.1 & - & - & - & 2 \\
\hline \multicolumn{7}{|c|}{ S. sonnei clinical strain } \\
\hline Extracts & Tetracycline & Gentamycin & Erythromycin & Chloramphenicol & Penicillin-G & Ciprofloxacin \\
\hline $\mathrm{TIH}_{2} \mathrm{O}$ & - & 2.1 & - & - & - & - \\
\hline TIMeOH & - & 2.3 & - & - & - & 1 \\
\hline TIETAC & - & 2.1 & - & - & - & 1 \\
\hline $\mathrm{TICHCl}_{3}$ & - & 2.1 & - & - & - & 1 \\
\hline TIHEX & - & - & - & - & - & 1 \\
\hline \multicolumn{7}{|c|}{ S. aureus } \\
\hline Extracts & Tetracycline & Gentamycin & Erythromycin & Chloramphenicol & Penicillin-G & Ciprofloxacin \\
\hline $\mathrm{TIH}_{2} \mathrm{O}$ & - & 2.5 & 1 & 1 & 1 & $\underline{4.5}$ \\
\hline TIMeOH & - & 2.1 & - & - & - & $\underline{8.1}$ \\
\hline TIETAC & 2.1 & - & - & - & - & $\underline{8.1}$ \\
\hline $\mathrm{TICHCl}_{3}$ & 2.1 & 2.1 & - & - & - & - \\
\hline TIHEX & - & 2.1 & - & - & - & 1 \\
\hline
\end{tabular}

$\mathrm{TI}=$ T. Impetiginos $a$ bark; $\mathrm{H}_{2} \mathrm{O}=$ water; $\mathrm{MeOH}=$ methanol; $\mathrm{ETAC}=$ ethyl acetate; $\mathrm{CHCl}_{3}=$ chloroform; $\mathrm{HEX}=$ hexane; Numbers indicates the mean FIC values calculated in duplicate; - = indicates that $\Sigma$ FIC could not be determined; Synergy $=\leq 0.5$; Additive $=>0.5-1.0$; NonInteractive $=>1.0-\leq 4$, Antagonistic $=>4.0$.

secretion ${ }^{12}$ and the growth of bacterial mediators of some autoimmune diseases. ${ }^{13}$ This report aimed to extend these previous studies by screening the extracts against bacterial gastrointestinal pathogens (alone and in combination with conventional antibiotics). Whilst we did detect some antibacterial activity in this study, most bacterial species examined were refractory to inhibition by the extracts. However, activity was observed for the methanolic, ethyl acetate, chloroform and hexane T. impetiginosa bark extracts towards $B$. cereus. This suggests that T. impetiginosa bark extracts contains components that could be used to treat diarrhoeal illness caused by B. cereus, despite the fact that the bacteriostatic/cidal effects are relatively mild. To our knowledge, this represents the first evidence that $T$. impetiginosa bark possesses bacterial growth inhibitory properties against this specific strain.

The combinational studies reported in this manuscript screened the $T$. impetiginosa bark extracts extracts for interactions with the conventional antibiotics. These studies are not only important to identify possible antimicrobial alternatives to overcome bacterial antibiotic resistance; they may also provide valuable information for clinical use of these therapies, where herbal therapy-conventional antibiotic interactions may occur.
Many people use herbal therapies and conventional antibiotics concurrently, without any understanding of the interactions that may occur between the different medicines. Natural products may have severe interactions in combination with conventional medicines, even when either component is safe when used alone. ${ }^{30}$ Also of concern, the efficacy of a therapy may be affected in combination with other medicines. Whilst, some combinations may have increased potency, other combinations may antagonize each other's effects, thereby decreasing the efficacy of the therapy. It is important to identify such combinations so that they can be avoided.

The T. impetiginosa bark extracts could potentiate the activity of some conventional antibiotics. Several additive combinatorial interactions were noted. In particular, the water and methanolic extracts potentiated the activity of erythromycin, chloramphenicol and ciprofloxacin against $B$. cereus. The aqueous extract also potentiated the activity of penicillin$G$ against the same bacterium. Similarly, the aqueous extract also produced additive effects when combined with erythromycin, penicillin-G and chloramphenicol against $S$. aureus. Interestingly, all extracts (except the aqueous extract) also produced additive effects in combination with 
ciprofloxacin against S. sonnei. Similarly, the mid-polarity ethyl acetate and chloroform extracts also produced additive interactions with ciprofloxacin against $B$. cereus. As such, these combinations would be beneficial for the treatment of diarrhoea, as they have greater efficacy than that of either component alone. Of the remaining combinations, the majority were either non-interactive, or were unable to be determined as at least one of the components in the combination showed no inhibition of bacterial growth when tested alone. Therefore, whilst using these combinations would have no additional therapeutic benefit, the components would not impede the activity of the other component.

Several combinations produced an antagonistic effect against $B$. cereus and S. aureus. Notably, all of these antagonistic combinations contained ciprofloxacin. Antagonistic interactions often occur when the chemical agent that stops bacteria from reproducing (bacteriostatic) reaches the site of infection before the one that kills bacteria (bactericidal). ${ }^{31}$ These specific combinations should be avoided in the treatment of diarrhoea and any other diseases caused by these bacteria. The mechanisms of action regarding additive or antagonistic effects of the combinations against bacterial growth were not examined in this study. However, they may involve the alteration of specific cellular components by the plant extract to facilitate changes in the bacterial growth properties. Further investigations are necessary in order to more definitively identify the mechanism(s) involved.

Whilst a detailed investigation of the phytochemistry of the T. impetiginosa bark extracts was beyond the scope of this study, the qualitative phytochemical screening allowed the major classes of secondary chemical components in the plant to be determined. Additionally, recent studies have identified several interesting compounds in T. impetiginosa bark extracts. Most of these studies have focused on lapachol due to its antineoplastic and antitumor effects. ${ }^{32,33}$ However, other studies have also identified furanonaphthoquinones, ${ }^{34,35}$ quinones, ${ }^{36}$ naphthoquinoes, ${ }^{37}$ benzoic acid, benzaldehyde derivatives ${ }^{38}$ as well as flavonoids. ${ }^{39}$ Further phytochemical purification and structural analysis studies are required to evaluate the growth inhibitory mechanism(s) and to identify the bioactive and potentiating (or antagonizing) extract components.

Our studies only examined the effects of the T. impetiginosa bark extracts against planktontic bacteria. Bacterial infections are generally much more difficult to treat if the bacteria form biofilms. Biofilms occurs when bacteria enter the body and attach to the surface of the infected tissue. They subsequently coordinate and synthesise adhesion sites between cells to form a three dimensional biofilm. The cells communicate via quorum sensing to regulate gene expression within the bacterium and increase the bacteria's resistance to antibiotic treatments. ${ }^{40}$ The biofilm community begins to grow through cell division and recruitment (of other bacteria, yeasts, minerals and host proteins) making it resistant to the immune system and exogenous antibiotics. ${ }^{40}$ This aspect of bacterial colonisation in vivo may greatly affect susceptibility and this requires attention. Furthermore, as bacteria in biofilms generally have MIC values at least an order of magnitude higher than in liquid cultures, it would be interesting to test whether T. impetiginosa bark extracts can also block biofilm formation by the bacterial strains reported in this manuscript and future studies are planned to examine this.

\section{CONCLUSION}

The results of this study demonstrate the potential of T. impetiginosa bark extracts as inhibitors of the growth of some bacterial species associated with gastrointestinal disaease and diarrhoea. All $T$. impetiginosa bark extracts were nontoxic, further indicating their suitability for prophylactic therapeutic usage. Further studies are required to isolate the inhibitory compounds and identify their antimicrobial mechanisms.

\section{ACKNOWLEDGEMENT}

Financial support for this work was provided by the Environmental Futures Research Institute, Griffith University.

\section{CONFLICT OF INTEREST}

The authors report no conflicts of interest.

\section{ABBREVIATIONS}

DMSO: Dimethyl sulfoxide; $\mathbf{L C}_{50}$ : The concentration required to achieve 50 \% mortality; MIC: Minimum inhibitory concentration; ZOI: Zone of inhibition.

\section{REFERENCES}

1. Cheesman MJ, Ilanko A, Blonk B, Cock IE. Developing new antimicrobial therapies: Are synergistic combinations of plant extracts/compounds with conventional antibiotics the solution?. Pharmacognosy Reviews. 2017:11(22):57-72. DOI: 10.4130/phrev.phrev_21_17

2. World Health Organization. Diarrhoea: Why children are still dying and what can be done. WHO, Geneva. 2009. http://apps.who.int/iris/bitstre am/10665/44174/1/9789241598415_eng.pdf

3. Unicef. 2016. http://data.unicef.org/child-health/diarrhoeal-disease.html.

4. Ilanko A, Cock IE. The interactive antimicrobial activity of conventional antibiotics and Petalostigma spp. extracts against bacterial triggers of some autoimmune inflammatory diseases. Pharmacognosy Journal. 2019;11(2):292-309. DOI: $10.5530 /$ pj.2019.11.45

5. Hutchings A, Cock IE. An interactive antimicrobial activity of Embilica officinalis Gaertn. fruit extracts and connentional antibiotics against some bacterial triggers of autoimmune inflammatory diseases. Pharmacognosy Journal. 2018;10(4):654-2. DOI: 10.5530/pj.2018.4.108

6. Mandeville A, Cock IE. Terminalia chebula Retz. fruit extracts inhibit bacterial triggers of some autoimmune diseases and potentiate the activity of tetracycline. Indian Journal of Microbiology. 2018;58(4):496-506. DOI: 10.1007/s12088018-0754-9

7. Hübsch Z, Zyl RV, Cock IE, Vuuren SFV. Interactive antimicrobial and toxicity profiles of conventional antimicrobials with Southern African medicinal plants. South African Journal of Botany. 2014;93:185-97. DOI: 10.1016/j. sajb.2014.04.005

8. Sirdaarta J, Matthews B, Cock IE. Kakadu plum fruit extracts inhibit the growth of the bacterial triggers of rheumatoid arthritis: Identification of stilbene and tannin components. Journal of Functional Foods. 2015;17:610-20. DOI: 10.1016/j.jff.2015.06.019

9. Ilanko A, Cock IE. The interactive antimicrobial activity of conventional antibiotics and Petalostigma spp. extracts against bacterial triggers of some autoimmune inflammatory diseases. Pharmacognosy Journal. 2019;11 (2):258-66.

10. Chikowe G, Mpala L, Cock IE. Callistemon linearis Schrad. and JC Wendl. ex tracts inhibit the growth of gram positive bacteria but have no effect on gram negative bacteria. Pharmacognosy Communications. 2019;9(2):39-46. DOI: 10.5530/pc.2019.2.10

11. Gomez CJR, Prieto JM, Heinrich M. Red lapacho (Tabebuia impetiginosa): A global ethnopharmacological commodity?. Journal of Ethnopharmacology. 2009;121(1):1-13.

12. Ryan RYM, Fernandez A, Miles J, Cock IE. Tabebuia impetiginosa bark extracts potently reduce pro-inflammatory cytokine secretion in human peripheral blood mononuclear cells. In Press. 2019.

13. Fernandez A, Cock IE. Tabebuia impetiginosa (Mart. Ex DC. Mattos) bark ex tracts inhibit the growth bacterial triggers of autoimmune diseases and potentiate the activity of some conventional antibiotics. Pharmacognosy Journal. 2019.

14. Wright MH, Matthews B, Arnold MSJ, Greene AC, Cock IE. The prevention of fish spoilage by high antioxidant Australian culinary plants: Shewanella putrefaciens growth inhibition. International Journal of Food Science and Technology. 2016;51(3):801-13. DOI: 10.1111/ijfs.13026

15. Lee CJ, Wright MH, Arnold MSJ, Greene AC, Cock IE. Inhibition of Streptococcus pyogenes growth by native Australian plants: New approaches towards the management of impetigo, pharyngitis and rheumatic heart disease. Pharmacognosy Communications. 2016;6(3):164-73. DOI: 10.5530/pc.2016.3.6

16. Courtney R, Sirdaarta J, Matthews B, Cock IE. Tannin components and inhibitory activity of Kakadu plum leaf extracts against microbial triggers of autoimmune inflammatory diseases. Pharmacognosy Journal. 2015;7(1):18-31. DOI: 10.5530/pj.2015.7.2

17. Cock IE. Antimicrobial activity of Callistemon citrinus and Callistemon salignus methanolic extracts. Pharmacognosy Communications. 2012;2(3):50-7.

18. Omer E, Eldhamy Al, Nassar M, Shalom J, White AR, Cock IE. Plantago squar rosa Murray extracts inhibit the growth of some bacterial triggers of autoim- 
mune diseases: GC-MS analysis of an inhibitory extract. Inflammopharmacology. 2018;27(2):373-85. DOI: 10.1007/s10787-018-0547-0

19. Arkhipov A, Sirdaarta J, Rayan P, McDonnell PA, Cock IE. An examination of the antibacterial, antifungal, anti-Giardial and anticancer properties of Kigelia africana fruit extracts. Pharmacognosy Communications. 2014;4(3):62-76. DOI: 10.5530/pc.2014.3.7

20. Blonk B, Cock IE. Interactive antimicrobial and toxicity profiles of Pittosporum angustifolium Lodd. extracts with conventional antibiotics. Journal of Integtrative Medicine. 2019;17(4):261-72. https://doi.org/10.1016/j.joim.2019.03.006

21. Maas H, Cock IE. Interactive antimicrobial and toxicity profiles of Glycyrrhiza glabra L. root extracts and conventional antibiotics against some bacterial triggers of autoimmune inflammatory diseases. Pharmacognosy Communications 2018;8(2):66-74

22. Ruebhart DR, Wickramasinghe W, Cock IE. Protective efficacy of the antioxidants vitamin $\mathrm{E}$ and Trolox against Microcystis aeruginosa and microcystin-LR in Artemia franciscana nauplii. Journal of Toxicology and Environmental Health Part A. 2009:72(24):1567-75.

23. Cock IE, Ruebhart DR. Comparison of the brine shrimp nauplii bioassay and the ToxScreen-II test for the detection of toxicity associated with Aloe vera (Aloe barbadensis Miller) leaf extract. Pharmacognosy Research. 2009;1(2):102-8.

24. Shalom J, Cock IE. Terminalia ferdinandiana Exell. fruit and leaf extracts inhibit proliferation and induce apoptosis in selected human cancer cell lines. Nutrition and Cancer. 2018;70(4):579-93. DOI: 10.1080/01635581.2018.1460680

25. Wright MH, Shalom J, Matthews B, Green AC, Cock IE. Terminalia ferdinandiana Exell: extracts inhibit Shewanella spp. growth and prevent fish spoilage. Food Microbiology. 2019;78:114-22.

26. O'Neill J. Antimicrobial resistance: Tackling a crisis for the health and wealth of nations. Reviews on Antimicrobial Resistance. 2014;20:1-16.

27. Amouzou A, Velez LC, Tarekegn H, Young M. One is too many: Ending child deaths from pneumonia and diarrhoea. UNICEF. New York, NY. 2016;1-74.

28. World Health Organization. Diarrhoeal disease. 2017. Retrieved from http:// www.who.int/en/news-room/fact-sheets/detail/diarrhoeal-disease.

29. Kapi A. The evolving threat of antimicrobial resistance: Options for action. Indian
Journal of Medical Research. 2014;139(1):182-3

30. Cock I. The safe usage of herbal medicines: Counter-indications, cross-reactivity and toxicity. Pharmacognosy Communications. 2015;5(1):2-50

31. Koech K, Wachira F, Ngure R, Wanyoko J, Bii C, Karori S. Antibacterial and synergistic activity of different tea crude extracts against antibiotic resistant $S$. aureus, E. coli and a clinical isolate of S. typhi. Science Journal of Microbiology. 2013;1-9.

32. DeSantana CF, DeLima O, D'albuquerque I, Lacerda AL, Martins DG. Antitumoral and toxicological properties of extracts of bark and various wood components of Pau d'arco (Tabebuia avellanedae). Revista do Instituto De Antibioticos, Universidade Federal De Pernambuco. 1968;8(1):89-94.

33. Ueda S, Umemura T, Dohguchi K, Matsuzaki T, Tokuda $H$, Nishino $H$, et al. Production of anti-tumour-promoting furano-naphthoquinones in Tabebuia avellanedae cell cultures. Phytochemistry. 1994;36(2):323-5.

34. DeOliveira AB, Raslan DS, DeOliveira GG, Maia JGS. Lignans and naphthoquinones from Tabebuia incana. Phytochemistry. 1993;34(5):1409-12.

35. Zani CL, DeOliveira AB, DeOliveira GG. Furanonaphthoquinones from Tabebuia ochracea. Phytochemistry. 1991;30(7):2379-81.

36. Sharma PK, Khanna RN, Rohatgi BK, Thomson RH. Tecomaquinone-III: A new quinone from Tabebuia pentaphylla. Phytochemistry. 1988;27(2):632-3.

37. Manners GD, Jurd L. A new naphthaquinone from Tabebuia guayacan. Phytochemistry. 1976;15:225-6

38. Wagner $\mathrm{H}$, Kreher B, Lotter $\mathrm{H}$, Hamburger MO, Cordell GA. Structure determination of new isomeric naphtho [2, 3-b] furan-4, 9-diones from Tabebuia avellanedae by the selective-INEPT technique. Helvetica Chimica Acta. 1989;72:65967.

39. Blatt CT, Salatino A, Salatino ML. Flavonoids of Tabebuia caraiba (Bignoniaceae). Biochemical Systematics and Ecology. 1996;24(1):89.

40. O'loughlin CT, Miller LC, Siryaporn A, Drescher K, Semmelhack MF, Bassle $\mathrm{BL}$. A quorum-sensing inhibitor blocks Pseudomonas aeruginosa virulence and biofilm formation. Proceedings of the National Academy of Sciences 2013:110(44):17981-6.

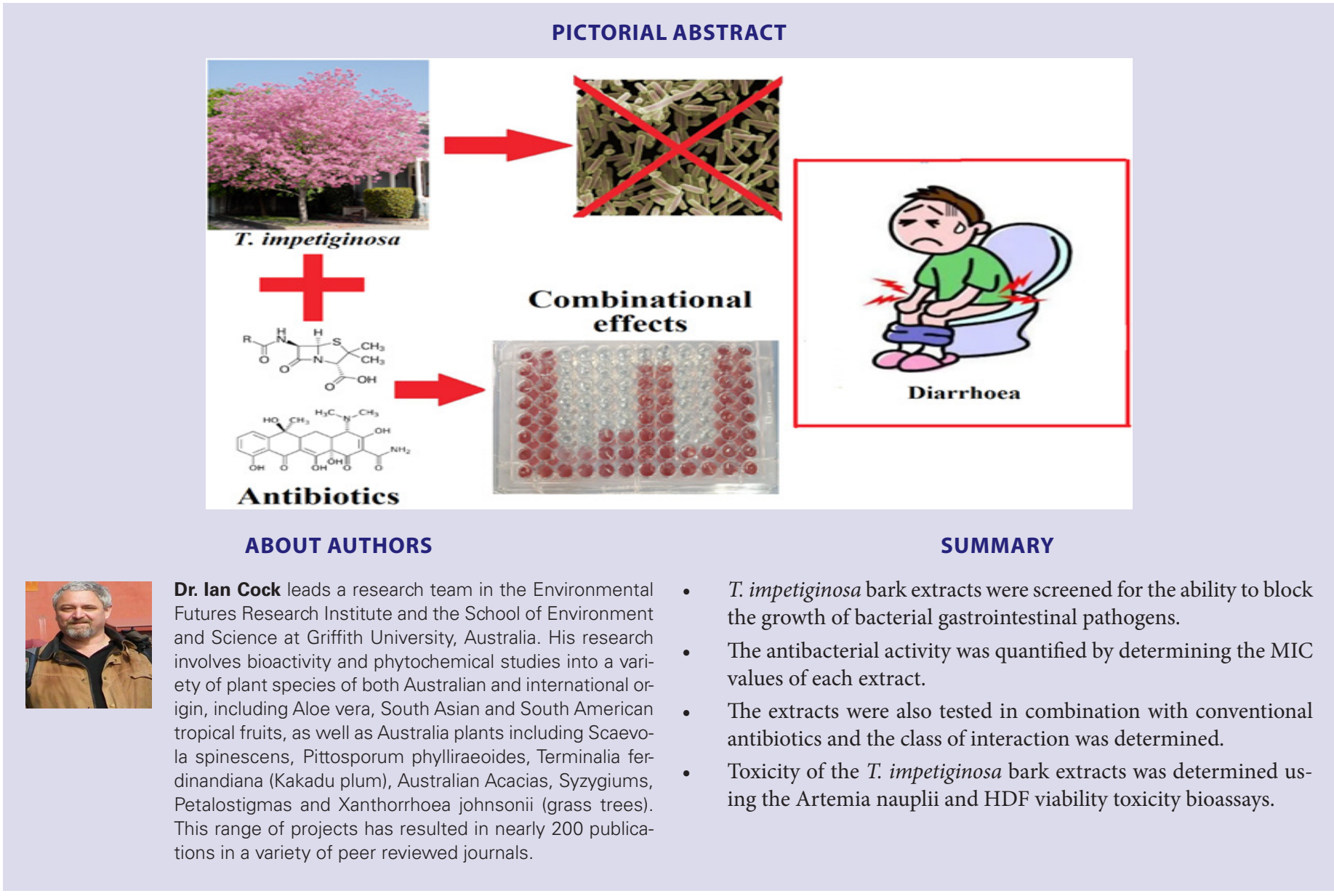

